\title{
Nutritional assessment interpretation on 22007 Spanish community-dwelling elders through the Mini Nutritional Assessment test
}

\author{
M Cuervo ${ }^{1}$, A García ${ }^{2}$, D Ansorena ${ }^{1}$, A Sánchez-Villegas ${ }^{3}$, MA Martínez-González ${ }^{4}$, \\ I Astiasarán ${ }^{1}$ and JA Martínez ${ }^{1, *}$ \\ 'Department of Food Sciences, Nutrition, Physiology and Toxicology, University of Navarra, Irunlarrea 1, \\ E-3 1080 Pamplona, Spain: ${ }^{2}$ Spanish Pharmacists Council, Madrid, Spain: ${ }^{3}$ Department of Clinical Sciences, \\ University of Las Palmas de Gran Canaria, Spain: ${ }^{4}$ Department of Epidemiology and Public Health, \\ University of Navarra, Pamplona, Spain
}

Submitted 29 March 2007: Accepted 14 January 2008: First published online 16 April 2008

\begin{abstract}
Objectives: To evaluate the prevalence of undernutrition among communitydwelling elderly people in Spain using the Mini Nutritional Assessment (MNA) and to analyse its distribution according to age, gender and residence region.

Design: Cross-sectional study assessing the nutritional status of elderly persons through both the short form and the full version of the MNA test.

Setting: Pharmacy offices across the whole country (Spain) were enrolled to recruit participants.

Subjects: A total of 22007 participants (8014 men and 13993 women), aged $\geq 65$ years, assessed during the last two months of 2005.

Results: According to MNA screening, $4 \cdot 3 \%$ subjects were classified as undernourished (MNA score $<17$ ) and $25 \cdot 4 \%$ were at risk of undernutrition (MNA score $\geq 17$ to $\leq 23 \cdot 5)$. The MNA short form correlated strongly with the full MNA version $(r=0 \cdot 85)$. MNA total score was significantly higher in men than in women $(25 \cdot 4$ (sD 3.7) v. 24.6 (SD 3.9); $P<0.001$ ) and lower in the oldest than in the youngest subjects $(P<0 \cdot 001)$ in both genders. According to regional distribution, the best nutritional status was found in elderly from the north of Spain excluding the north-west area.

Conclusions: Female gender, older age and living in the south half or northwest of the country were associated with higher rates of undernutrition among community-dwelling elderly persons in Spain.
\end{abstract}

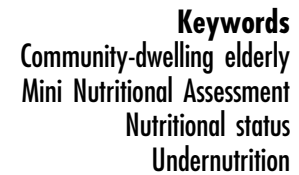

Elderly people have an increased risk of nutrient and energy deficiencies (i.e. undernutrition) compared with middleaged adults ${ }^{(1)}$. One of the main reasons is that ageing is often accompanied by a variety of physiological and psychological impairments, as well as by economic and social changes that may adversely affect nutritional status ${ }^{(2)}$. On one hand, physiological and pathological disturbances can bring changes in dietary habits and nutrient metabolism ${ }^{(3)}$. On the other hand, social isolation and economic constraints often influence the preparation and consumption of food ${ }^{(4)}$. This situation is commonly aggravated by associated diseases and pharmacological treatments, which is a frequent situation in the aged person ${ }^{(5,6)}$.

Poor nutritional status in older people is related to increased demands on health services, lengthier hospital stays and is recognized as an important predictor of morbidity and mortality ${ }^{(7)}$; thus it represents a significant public health burden, as well as one that should concern all health professionals involved in individual or group contacts with the elderly ${ }^{(3)}$. An adequate evaluation of elderly people's nutritional status and the associated factors (socio-economic, cultural, physiological, pathological, etc.) that can adversely affect nutritional outcomes should accompany a reduction of undernutrition prevalence. As a consequence, quality of life would be improved, the number of hospitalized and institutionalized aged persons would be reduced, and the public expense to cover health and social demands from this population group would also be decreased ${ }^{(8)}$.

It is estimated that the rate of people aged $\geq 65$ years in EU-25 will increase from its current level of $16 \%$ to around $30 \%$ of the total population by $2050^{(9,10)}$. Indeed, the growing number of elderly individuals all around the world is linked to high costs of treatments that could be reduced dramatically by appropriate, nutritionoriented care. 
In this context, more than seventy tests or tools have been reported that are currently available for undernutrition detection but they differ in their criteria, cut-off points, ease of use and acceptability ${ }^{(11)}$. Among these methods, the Mini Nutritional Assessment (MNA) has been revealed as probably the best screening tool to detect malnourished elders and those at risk for malnutrition. Thus, 15 years after it was published, the MNA, which was especially developed for elderly people, remains the gold standard for ambulatory living elders ${ }^{(12)}$. Moreover, it appears to be the most suitable and reliable tool for the detection of undernutrition in any way of living ${ }^{(13)}$ and provides the health professional a unique opportunity to design specific plans for nutritional treatment. Since its validation in 1994, the MNA has been used in a number of studies and translated into more than twenty languages ${ }^{(14)}$. Nowadays, it is recognized as a well-validated tool, with high sensitivity, specificity and reliability ${ }^{(15)}$.

The aim of the present study was to assess the prevalence of undernutrition in the elderly population in Spain, applying the MNA test in a large population sample ( $n 22$ 007) and analysing the impact of age, gender and residence region. The suitability of the short form of the MNA test for these purposes was also evaluated.

\section{Subjects and methods}

\section{Subject recruitment}

The present cross-sectional study was conducted during November and December 2005 all over Spain. The study population included elders ( $n$ 22 007) from all regions in Spain, with age (65 years or older) being the only criterion for inclusion. Volunteers were recruited by community pharmacists who had contact with community-dwelling elders. All the participants were specifically asked if they would be willing to take part in the study. Only those who accepted were enrolled.

Health professionals (3251 community pharmacists) were recruited through the Spanish Pharmacists Council to collect data. All of them received a training session and an extensive document with the information needed about the survey, the correct way to formulate every question and a decision tree to interpret the result of the survey in each case ${ }^{(16)}$. This type of training session for health professionals usually has a positive impact on the results of the MNA test ${ }^{(17)}$. Furthermore, a video conference explaining the study was broadcast to every provincial pharmacist college, and a website was available for all pharmacists involved in the study to ensure harmonization among interviewers.

\section{Data collection}

Data were collected by using the MNA test, encoded for further optical reading (SCANMARK ES2800 ${ }^{\mathrm{TM}}$ Optical Mark Reader; Scantron Corporation, Tustin, CA, USA) with an optical model reading (OMR) programme (JBLEE, Madrid, Spain). About 50000 encoded questionnaires were printed with a magnetic band. The questionnaires were sent to each provincial pharmacist college, depending on the number of interested community pharmacists.

In addition to specific MNA questions, other information was requested: postal code (to identify the region), age, gender, weight and height, and place where the interview took place. A total of 26484 filled questionnaires were received and, after careful clean-up to discard subjects under 65 years old, non-valid or illegible data (among other causes), the final complete sample reached 22007.

\section{Mini nutritional assessment}

The MNA test (Table 1) can be divided into two distinct parts: the short form (screening questionnaire) and the full version $^{(18,19)}$. The MNA short form consists of six questions concerning recent appetite and weight loss, mobility, acute disease or psychological stress, neuropsychological problems and BMI. A total score of 12 and above (maximum is 14) indicates satisfactory nutritional status, so there is no need to follow with the second part of the MNA. A screening score of 11 and below suggests possible undernutrition status and it is necessary to complete the full version of the MNA. This second part has twelve additional questions with a maximum possible score of 16 points. The MNA total score (maximum is 30) distinguishes between elders with adequate nutritional status (score $\geq 24$ ), risk of undernutrition (score $\geq 17$ to $\leq 23 \cdot 5$ ) and undernutrition (score $<17$ ). The full MNA was done for all subjects.

BMI was calculated as weight (kg) divided by the square of height $(\mathrm{m})$. Weight was measured to the nearest kilogram and height to the nearest centimetre. For all individuals aged 18 years or older, the $\mathrm{WHO}^{(20)}$ and some national health agencies ${ }^{(21,22)}$ recommend that overweight be defined as BMI $=25 \cdot 0-29 \cdot 9 \mathrm{~kg} / \mathrm{m}^{2}$ and obesity as $\mathrm{BMI} \geq 30 \cdot 0 \mathrm{~kg} / \mathrm{m}^{2}$, although it is clear that BMI in the overweight range is not associated with a significantly increased risk of mortality in the elderly ${ }^{(23)}$.

For analysis of the regional prevalence of undernutrition in the Spanish elderly population, the ACNielsen areas were selected (www.acnielsen.es). These areas have been established taking into account socioeconomic criteria and consumption patterns to obtain nine geographical areas in Spain.

\section{Statistical analysis}

Statistical analyses were performed with the SPSS for Windows XP statistical software package version $13 \cdot 0$ (SPSS Inc., Chicago, IL, USA) following criteria described elsewhere ${ }^{(24)}$. Means and standard deviations were used as descriptive statistics. Student's $t$ tests were performed to compare means for age, weight, height and BMI between men and women and Mann-Whitney $U$ tests were used to compare different scores in the short and full MNA test between both genders. Assuming the full MNA test as the 
Table 1 Questions of the Mini Nutritional Assessment (MNA): short form (screening) and the full version ${ }^{(18,19)}$, and frequency distribution (in parentheses) concerning the eighteen MNA questions in a community-dwelling elderly Spanish population $(n=22007)$

1. Has food intake declined over the past three months due to loss of appetite, digestive problems, chewing or swallowing difficulties? Severe loss of appetite $=0 \quad(3 \cdot 6 \%)$

Moderate loss of appetite $=1 \quad(19 \cdot 6 \%)$

No loss of appetite $=2 \quad(76.8 \%)$

2. Weight loss during the last three months?

Greater than $3 \mathrm{~kg}(6.6 \mathrm{lb})=0 \quad(6.1 \%)$

Does not know $=1 \quad(10.5 \%)$

Between 1 and $3 \mathrm{~kg}(2.2$ and $6.6 \mathrm{lbs})=2 \quad(16.1 \%)$

No weight loss $=3 \quad(67 \cdot 3 \%)$

3. Mobility?

Bed- or chair-bound $=0 \quad(2.4 \%)$

Able to get out of bed/chair but does not go out $=1 \quad(5 \cdot 6 \%)$ Goes out $=2 \quad(92 \cdot 1 \%)$

4. Has the patient suffered psychological stress or acute disease in the past three months?

Yes $=0 \quad(27 \cdot 9 \%) \quad$ No $=2 \quad(72.1 \%)$

5. Neuropsychological problems?

Severe dementia or depression $=0 \quad(2 \cdot 4 \%)$

Mild dementia $=1 \quad(21 \cdot 7 \%)$

No psychological problems $=2 \quad(75.9 \%)$

6. BMI? (weight in $\mathrm{kg} /$ height in $\mathrm{m}^{2}$ )

$\mathrm{BMI}<19=0 \quad(1.3 \%)$

$19 \leq \mathrm{BMI}<21=1 \quad(3 \cdot 8 \%)$

$21 \leq \mathrm{BMI}<23=2 \quad(8 \cdot 3 \%)$

$\mathrm{BMI} \geq 23=3 \quad(86.6 \%)$

SCREENING SCORE (subtotal max. 14 points)

$\geq 12$ points $=$ Not at risk of undernutrition $(33.1 \%)$

$\leq 11$ points $=$ Possible undernutrition $(66.9 \%)$

7. Lives independently (not in a nursing home or hospital)? No $=0 \quad(15.9 \%) \quad$ Yes $=1 \quad(84.1 \%)$

8. Takes more than three prescription drugs per day? $\begin{array}{lll}Y e s=0 & (57 \cdot 1 \%) \quad \text { No }=1 \quad(42.9 \%)\end{array}$

9. Pressure sores or skin ulcers?

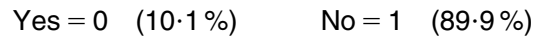

10. How many full meals does the patient eat daily?

$1 \mathrm{meal}=0 \quad(2.4 \%)$

2 meals $=0.5 \quad(17 \cdot 0 \%)$

3 meals $=1 \quad(80.5 \%)$
11. Selected consumption markers for protein intake

Consumes at least one serving of dairy products per day? Yes $(90.3 \%) \quad$ No $(9.7 \%)$

Consumes two or more servings of legumes or eggs per week? Yes $(83.6 \%) \quad$ No $(16.4 \%)$

Consumes meat, fish or poultry every day?

Yes $(83.8 \%) \quad$ No $(16.2 \%)$

If 0 or 1 yes $=0 \quad(6 \cdot 8 \%)$

If 2 yes $=0.5 \quad(28.0 \%)$

If 3 yes $=1 \quad(65 \cdot 2 \%)$

12. Consumes two or more servings of fruits or vegetables per day? No $=0 \quad(16 \cdot 8 \%) \quad$ Yes $=1 \quad(83.2 \%)$

13. How much fluid is consumed per day?

Less than 3 cups $=0 \quad(18.5 \%)$

3 to 5 cups $=0.5 \quad(45 \cdot 4 \%)$

More than 5 cups $=1 \quad(36.0 \%)$

14. Mode of feeding

Unable to eat without assistance $=0 \quad(1.9 \%)$

Self-fed with some difficulty $=1 \quad(5 \cdot 1 \%)$

Self-fed without any problem $=2 \quad(93.0 \%)$

15. Self-view of nutritional status

Views self as being malnourished $=0 \quad(0.3 \%)$

Views self as having no nutritional problem $=1 \quad(12 \cdot 4 \%)$ Is uncertain of nutritional state $=2 \quad(87 \cdot 2 \%)$

16. In comparison with other people of the same age, how do they consider their health status?

Not as good $=0 \quad(11.5 \%)$

Does not know $=0.5 \quad(10.6 \%)$

As good $=1 \quad(39.5 \%)$

Better $=2 \quad(38.4 \%)$

17. Mid upper-arm circumference (MUAC) in $\mathrm{cm}$

$<21=0 \quad(4 \cdot 8 \%)$

$21-22=0.5 \quad(11 \cdot 2 \%)$

$>22=1 \quad(84.0 \%)$

18. Calf circumference (CC) in $\mathrm{cm}$

$<31=0 \quad(21.0 \%)$

$\geq 31=1 \quad(79 \cdot 0 \%)$

TOTAL SCORE (total max. 30 points)

$\geq 24$ points $=$ Not at undernutrition risk $(4.3 \%)$

$17-23.5$ points $=$ Undernutrition risk $(25.4 \%)$

$<17$ points $=$ Undernutrition $\quad(70 \cdot 3 \%)$ gold standard, the correlation between the short form and the full version of the MNA test was analysed by Spearman's test for correlations. Stepwise linear multiple regression analyses were used to identify the questions in the MNA which best predicted the MNA short and total scores. In addition, the sensitivity, specificity and predictive values were calculated to assess the association between the two MNA scores (short form and full version) regarding classification of undernutrition and undernutrition risk. The area under the receiver-operating characteristic (ROC) curve was used to assess the ability of the short form to predict values of the full MNA. Finally, ANOVA and a post boc Tukey $b$ test were performed to compare the MNA score distribution among different Spanish regions.

\section{Results}

Table 2 shows the description of the studied population. A total of 22007 elderly individuals were distributed as
13993 women (63.6\%) and 8014 men (36.4\%), with mean age of 75.2 years at evaluation. Their mean weight was $70.7 \mathrm{~kg}(76.4 \mathrm{~kg}$ in men and $67.4 \mathrm{~kg}$ in women) and their mean height was $159 \mathrm{~cm}(166 \mathrm{~cm}$ in men and $155 \mathrm{~cm}$ in women), resulting in a mean body mass index of $28 \cdot 0 \mathrm{~kg} / \mathrm{m}^{2}\left(27 \cdot 7 \mathrm{~kg} / \mathrm{m}^{2}\right.$ in men and $28 \cdot 1 \mathrm{~kg} / \mathrm{m}^{2}$ in women $)$. As expected, there were significant differences $(P<0 \cdot 001)$ between men and women in the anthropometric measurements.

The mean MNA score obtained in the two steps (short and full) for men (12.4 and 25.4 points) and women (11.9 and 24.6 points) showed statistically significant differences between genders $(P<0 \cdot 001)$, with an average of $12 \cdot 1$ points in the short form and 24.9 points in the full version when the overall sample was considered (Table 2).

A Spearman correlation test gave a high association value between the short and the full MNA tests $(r=0 \cdot 85$; $P<0 \cdot 001)$. A comparison between the number of subjects who were classified as possibly undernourished according to the MNA short form and the number so 
Table 2 Descriptive characteristics of the elderly Spanish population ( $n$ 22 007) participating in the present survey

\begin{tabular}{|c|c|c|c|c|c|c|}
\hline & \multicolumn{2}{|c|}{ Men $(n$ 8014) } & \multicolumn{2}{|c|}{ Women (n 13993) } & \multicolumn{2}{|c|}{ Total (n 22007$)$} \\
\hline & Mean & SD & Mean & SD & Mean & SD \\
\hline Age (years) & $75 \cdot 2$ & $6 \cdot 6$ & $75 \cdot 2$ & $6 \cdot 9$ & $75 \cdot 2$ & $6 \cdot 8$ \\
\hline Weight (kg) & $76 \cdot 4^{*}$ & $12 \cdot 3$ & $67 \cdot 4$ & $12 \cdot 4$ & $70 \cdot 7$ & $13 \cdot 1$ \\
\hline Height (cm) & $166 \cdot 2^{*}$ & $7 \cdot 6$ & $154 \cdot 9$ & $7 \cdot 4$ & $159 \cdot 0$ & $9 \cdot 2$ \\
\hline BMI $\left(\mathrm{kg} / \mathrm{m}^{2}\right)$ & $27 \cdot 7^{\star}$ & $4 \cdot 1$ & $28 \cdot 1$ & $5 \cdot 0$ & $28 \cdot 0$ & $4 \cdot 7$ \\
\hline MNA screening score & $12 \cdot 4^{\star *}$ & $2 \cdot 1$ & $11 \cdot 9$ & $2 \cdot 3$ & $12 \cdot 1$ & $2 \cdot 2$ \\
\hline MNA total score & $25 \cdot 4^{\star \star}$ & $3 \cdot 7$ & $24 \cdot 6$ & $3 \cdot 9$ & $24 \cdot 9$ & $3 \cdot 9$ \\
\hline
\end{tabular}

MNA, Mini Nutritional Assessment.

Mean values were significantly different from those of women: ${ }^{*} P<0.001$ (Student's $t$ test), ${ }^{\star *} P<0.001$ (Mann-Whitney $U$ test).

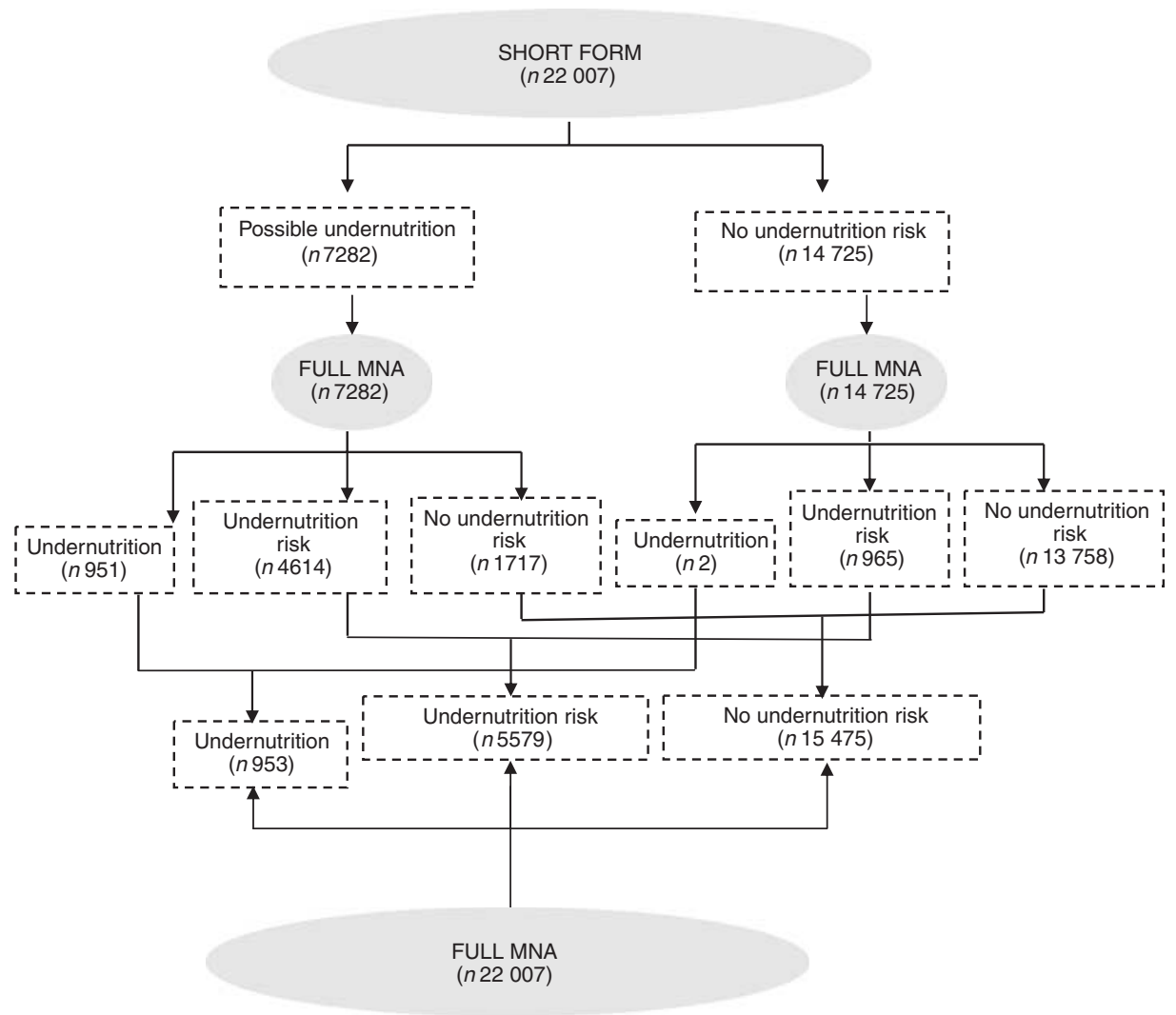

Fig. 1 Decision tree to assist in determining some calculations (MNA, Mini Nutritional Assessment)

classified according to the full version is shown in Fig. 1. According to the total MNA score about $4 \cdot 3 \%$ ( $n$ 953) of the population studied was undernourished, $25 \cdot 4 \%$ ( $n$ 5579) was at risk for being undernourished and $70 \cdot 3 \%$ ( $n$ 15 475) had no undernutrition risk. The frequency distribution of the responses to every question of the MNA is reported in Table 1.

As Fig. 1 shows, 7282 individuals presented a situation of possible undernutrition using the MNA short form which indicated the necessity to complete the full MNA. From those 7282 elders, 951 were classified as undernourished, 4614 were at undernutrition risk and the rest were in a situation of no undernutrition risk with the full MNA. From the 14725 individuals who were in a no undernutrition risk situation using the MNA short form, two cases revealed undernutrition, 965 were at undernutrition risk and 13758 showed no undernutrition risk with the full MNA. So, the sensitivity of the MNA short form with respect to the full MNA (used as the gold standard), i.e. the proportion of 'undernourished' or 'at risk' individuals classified as possible undernutrition by the MNA short form who were correctly identified as such by the MNA full version, was $85 \cdot 2 \%(=5565 / 6532)$. The specificity of the MNA short form, i.e. the proportion of 'well nourished' individuals classified by the MNA short form who were correctly identified as such by the MNA full version, was $88.9 \%(=13758 / 15475)$. The positive predictive value, i.e. the proportion of subjects classified by the MNA short form as being in a situation of possible undernutrition who were correctly identified as such by 
the MNA full version, was $76 \cdot 4 \%(=5565 / 7282)$. Finally, the negative predictive value, defined as the proportion of subjects classified by the MNA short form as being 'well nourished' who were correctly identified as such by the MNA full version, was $93 \cdot 4 \%(=13758 / 14725)$. The ROC curve was also plotted (Fig. 2) showing an area under the curve of $0 \cdot 942$.

Stepwise linear multiple regression analyses were used to identify those questions in the MNA that best predicted

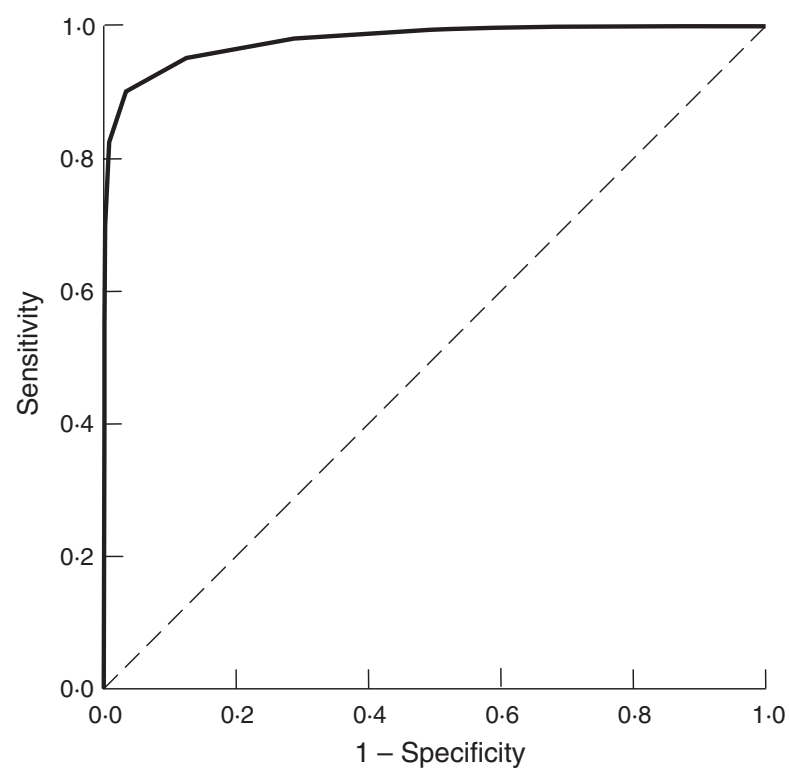

Fig. 2 Receiver-operating characteristic curve for the studied sample ( $n 22$ 007) applying the Mini Nutritional Assessment (MNA) short form as compared with the full MNA. Area under the curve is 0.942 the total score, not only for the whole sample but also separately for men and women. The importance, in the whole population and for men and women separately, of the questions included in MNA is reported in decreasing order of statistical contribution in Table 3.

The evolution of BMI and total MNA score with age in both genders is presented in Fig. $3 \mathrm{a}$ and $3 \mathrm{~b}$, respectively. Age was represented in ten categories (from 65-66 years to $\geq 85$ years). Increasing age was associated with decreasing total MNA score for all participants, men and women. However, BMI showed a decrease from 71-72 years old for men and from 75-76 years old for women. There were significant differences between the genders in every age category for MNA total score, but not in every age category for BMI. The average total MNA score was higher in men than in women in all age groups $(P<0 \cdot 05)$. Attending to BMI criteria $^{(25)}$ the obesity distribution in both genders was also analysed, showing that $25.5 \%$ of men and $33.0 \%$ of women presented $\mathrm{BMI} \geq 30 \cdot 0 \mathrm{~kg} / \mathrm{m}^{2}$. However, a total of eighty-eight obese subjects presented MNA score of $<17$ points, of whom sixteen were men and seventy-two were women.

Finally, Fig. 4 shows the MNA full score according to the nine Spanish regions defined by ACNielsen. ANOVA revealed that there were statistical differences among all Spanish regions $(P<0 \cdot 001)$. Scores higher than $25 \cdot 0$ points were found in the metropolitan area of Madrid, middle-north and north-east areas, while scores lower than 24.6 points were obtained in the south area, Canary Islands and north-west regions. Intermediate values ranging from $24 \cdot 84$ to 24.97 points were obtained in the middle-east and centre regions and in the metropolitan area of Barcelona.

Table 3 Proportion of total variability in the MNA score $\left(R^{2}\right)$ explained by individual MNA questions $(n 22007)$

\begin{tabular}{|c|c|c|c|c|c|c|c|c|}
\hline \multirow[b]{3}{*}{ MNA question } & \multicolumn{6}{|c|}{ Linear regression (individual variables) } & \multirow{2}{*}{\multicolumn{2}{|c|}{$\begin{array}{c}\begin{array}{c}\text { Stepwise regression } \\
\left.\text { (cumulative } R^{2}\right)\end{array} \\
\text { Total }(n 22007)\end{array}$}} \\
\hline & \multicolumn{2}{|c|}{ Total (n 22 007) } & \multicolumn{2}{|c|}{ Men (n 8014) } & \multicolumn{2}{|c|}{ Women (n 13993) } & & \\
\hline & $R^{2}$ & $P$ & $R^{2}$ & $P$ & $R^{2}$ & $P$ & $R^{2}$ & $P$ \\
\hline Food intake decline & $0 \cdot 379$ & $<0 \cdot 001$ & $0 \cdot 398$ & $<0.001$ & $0 \cdot 365$ & $<0.001$ & $0 \cdot 379$ & $<0.001$ \\
\hline Weight loss during the last 3 months & $0 \cdot 359$ & $<0.001$ & 0.383 & $<0.001$ & $0 \cdot 346$ & $<0.001$ & 0.547 & $<0.001$ \\
\hline Self-perceived nutritional status & $0 \cdot 349$ & $<0 \cdot 001$ & 0.362 & $<0 \cdot 001$ & $0 \cdot 341$ & $<0.001$ & 0.644 & $<0.001$ \\
\hline Self-perceived health status & $0 \cdot 327$ & $<0 \cdot 001$ & $0 \cdot 341$ & $<0.001$ & $0 \cdot 317$ & $<0.001$ & $0 \cdot 720$ & $<0.001$ \\
\hline Neuropsychological problems & $0 \cdot 291$ & $<0 \cdot 001$ & $0 \cdot 285$ & $<0.001$ & $0 \cdot 286$ & $<0.001$ & $0 \cdot 779$ & $<0.001$ \\
\hline Psychological stress & $0 \cdot 278$ & $<0.001$ & $0 \cdot 281$ & $<0.001$ & $0 \cdot 271$ & $<0.001$ & $0 \cdot 826$ & $<0.001$ \\
\hline Ability to eat & $0 \cdot 240$ & $<0.001$ & $0 \cdot 262$ & $<0.001$ & $0 \cdot 232$ & $<0.001$ & $0 \cdot 864$ & $<0.001$ \\
\hline Mobility & $0 \cdot 208$ & $<0 \cdot 001$ & $0 \cdot 219$ & $<0.001$ & $0 \cdot 201$ & $<0.001$ & $0 \cdot 894$ & $<0.001$ \\
\hline Mid upper-arm circumference & $0 \cdot 198$ & $<0 \cdot 001$ & $0 \cdot 176$ & $<0.001$ & $0 \cdot 205$ & $<0.001$ & 0.914 & $<0.001$ \\
\hline $\mathrm{BMI}$ & $0 \cdot 162$ & $<0 \cdot 001$ & $0 \cdot 150$ & $<0.001$ & $0 \cdot 163$ & $<0.001$ & 0.931 & $<0.001$ \\
\hline Calf circumference & $0 \cdot 159$ & $<0 \cdot 001$ & $0 \cdot 155$ & $<0.001$ & $0 \cdot 155$ & $<0.001$ & 0.946 & $<0.001$ \\
\hline Independence & $0 \cdot 122$ & $<0 \cdot 001$ & $0 \cdot 112$ & $<0.001$ & $0 \cdot 131$ & $<0.001$ & 0.959 & $<0.001$ \\
\hline Number of meals eaten daily & $0 \cdot 122$ & $<0.001$ & $0 \cdot 106$ & $<0.001$ & $0 \cdot 130$ & $<0.001$ & 0.970 & $<0.001$ \\
\hline Prescription drugs & $0 \cdot 114$ & $<0 \cdot 001$ & $0 \cdot 117$ & $<0.001$ & $0 \cdot 111$ & $<0.001$ & 0.979 & $<0.001$ \\
\hline Fruits or vegetables intake & 0.094 & $<0.001$ & 0.098 & $<0.001$ & $0 \cdot 101$ & $<0.001$ & 0.986 & $<0.001$ \\
\hline Protein intake & 0.094 & $<0 \cdot 001$ & 0.083 & $<0.001$ & $0 \cdot 103$ & $<0.001$ & 0.992 & $<0.001$ \\
\hline Fluid consumption & 0.076 & $<0 \cdot 001$ & 0.081 & $<0.001$ & 0.072 & $<0.001$ & 0.997 & $<0.001$ \\
\hline Skin problems & 0.062 & $<0 \cdot 001$ & 0.064 & $<0.001$ & 0.063 & $<0.001$ & $1 \cdot 000$ & $<0.001$ \\
\hline
\end{tabular}

MNA, Mini Nutritional Assessment. 

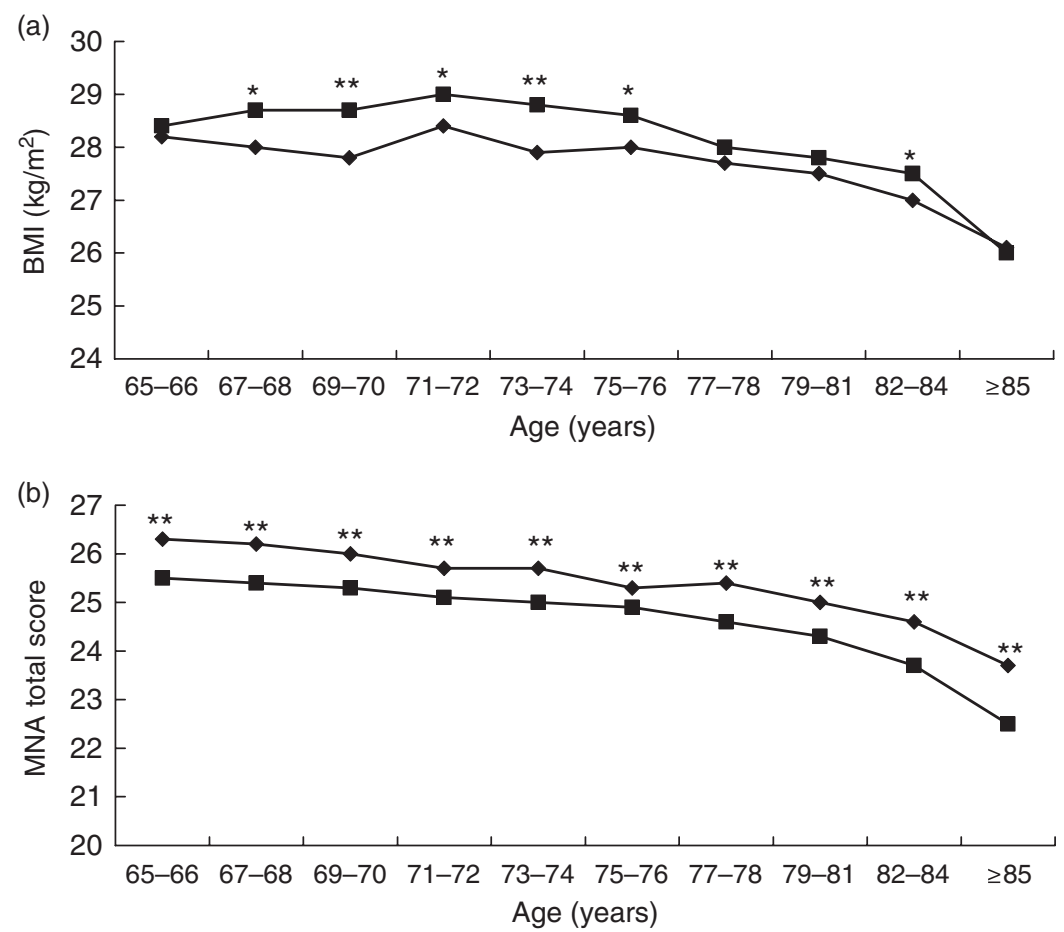

Fig. 3 Change of (a) BMI and (b) Mini Nutritional Assessment (MNA) total score with age for men (- - and women (- - ). Mean values were significantly different from those of women: ${ }^{\star} P<0.05,{ }^{* \star} P<0.001$

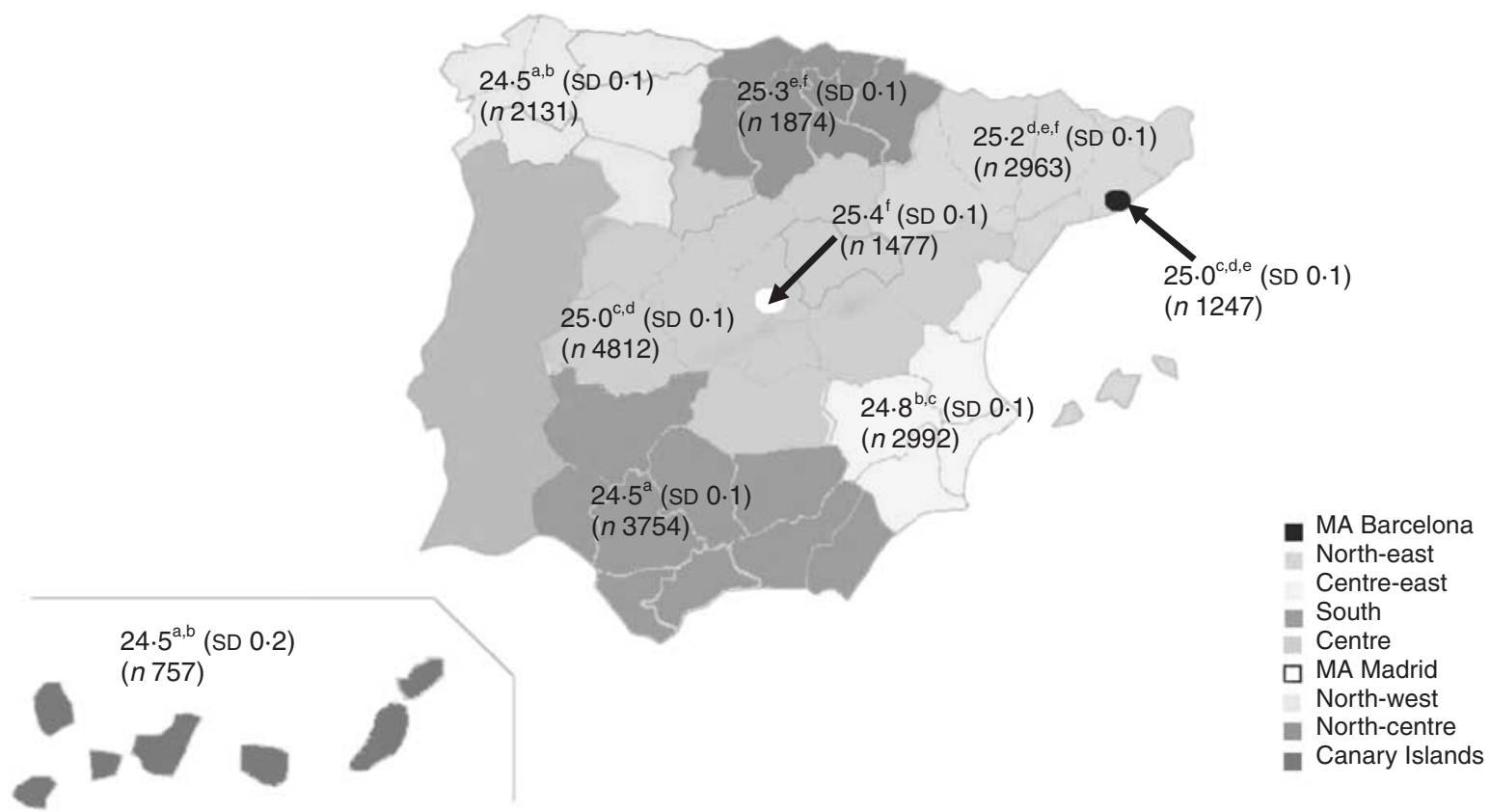

Fig. 4 Distribution of Mini Nutritional Assessment total score in Spain among ACNielsen regions. Values are means and their standard deviations. ${ }^{\mathrm{a}, \mathrm{b}, \mathrm{c}, \mathrm{d}, \mathrm{e}, \mathrm{f}}$ Mean values with unlike superscript letters were significantly different $(P<0 \cdot 05)$

\section{Discussion}

The most commonly used assessment tools to detect undernutrition in the elderly are the Malnutrition Universal Screening Tool (MUST), Subjective Global Assessment (SGA), Nutritional Risk Screening (NRS 2002) and MNA.
After many comparative studies among all of them, the MNA remains the gold standard for free-living elderly persons ${ }^{(12)}$, being used in a range of settings ${ }^{(14)}$.

The prevalence of malnutrition in European and American populations due to one or more nutritional deficiencies ranges from 1 to $15 \%$ in ambulatory living 
elders, from 25 to $60 \%$ in institutionalized elders and from 35 to $65 \%$ in hospitalized patients ${ }^{(3,26-28)}$. In Spain, this test has also been used in some surveys to detect the prevalence of undernutrition, but most of them were carried out in hospitalized or institutionalized elderly ${ }^{(29-31)}$. The few surveys that have been conducted among free-living elderly were done in just one geographical region and with a maximum population of $360^{(32,33)}$. The present study analysed the situation of elderly persons in the whole country, evaluating a total of 22007 people. The results obtained showed that $4 \cdot 3 \%$ of the community-dwelling elderly Spanish population is affected by undernutrition and $25 \cdot 4 \%$ presents a risk of undernutrition. These values were higher in women ( $4.8 \%$ of undernutrition and $28.0 \%$ at risk) than in men $(3.4 \%$ of undernutrition and $20 \cdot 8 \%$ at risk).

These findings are in accordance with data reported in a smaller group in Palma de Mallorca, Spain by Tur et $a l^{(32)}$, which revealed that $1 \%$ of male and $5 \%$ of female free-living elders were undernourished. Furthermore, Morillas et al. ${ }^{(33)}$ found similar results in Murcia, another region in the south of the country. This survey evidenced that $17 \%$ of the studied elderly people had a likely risk for undernutrition, with $3 \%$ of undernourished aged persons. Other studies found similar results in Europe, with sample size ranging from 351 to 10000 , using the same screening tool ${ }^{(13,34,35)}$.

The stepwise multiple regression analysis highlighted the questions in the MNA which were the most predictive to the total score. The questions concerning food intake decline, weight loss and self-perceived nutritional and health status were identified as the most important factors, followed by neuropsychological problems, psychological stress, ability to eat, mobility, mid upper-arm circumference and BMI. Within these ten questions are the six that make up the short form of the screening tool, which was chosen not only by its good correlation with total score, but also by avoiding items that were redundant, required special training to administer, involved difficult subjective recall, or produced too many missing or 'don't know' answers ${ }^{(18)}$. Skin problems, fluid consumption, protein intake and fruits or vegetables intake showed the weakest correlations with the total MNA score. Earlier findings reported similar results, with these items among the questions with the lower correlations ${ }^{(18,36,37)}$.

The regression analyses done separately for men and women showed some slight differences between them concerning the statistical contribution of items to the model: mid upper-arm circumference, BMI, independence, number of meals and protein intake had more influence on MNA total score for women than for men. In contrast, mobility and prescription drugs showed more influence on MNA score for men than for women. These differences could explain, at least in part, some of the differences in nutritional status between men and women.

The MNA short form was strongly correlated with the total MNA score $(r=0 \cdot 85)$, although this value was lower than the one obtained in the development of the short MNA form using the same cut-off point of $\geq 11$ as normal nutrition $(r=0.94)^{(18)}$.

Grouping the final MNA categories 'undernutrition' and 'undernutrition risk' against 'no undernutrition risk' to study the association of grades with the MNA short form, we obtained a sensitivity of $85 \cdot 2 \%$, a specificity of $88.9 \%$, a positive predictive value of $76.4 \%$ and a negative predictive value of $93.4 \%$ for predicting undernutrition risk. Taking into account that all of these results are high, it can be suggested that the MNA short form is a good option to screen large aged populations in Spain, in order to examine in more detail only those individuals with possible undernutrition identified using the MNA short form. Moreover, ROC curve analysis showed that the MNA short form had 'good to excellent' agreement $(\boldsymbol{\kappa}=0 \cdot 717)$ beyond chance with the MNA full version to rule out undernutrition risk $(P<0 \cdot 001)$. A potential limitation of the present survey is that the sample might be not fully representative, but in support of the validity of the study it was carried out in a high number of volunteers. Furthermore, the distribution according to ACNielsen regions and the outcome and data obtained are in agreement with other studies carried out with lower numbers of participants ${ }^{(32,33,38)}$.

The data concerning the estimation of BMI $\left(\mathrm{kg} / \mathrm{m}^{2}\right)$ evidenced that $43.0 \%$ of the studied sample was overweight and $30 \cdot 2 \%$ was obese, which suggests that not only undernutrition is important in the elderly population. Overweight rates in men and women were similar to the prevalence reported by Gutierrez-Fisac et $a l^{(38)}$, although obesity prevalence found in the present survey was lower than that found by those researchers $(36 \cdot 7 \%)$. These different obesity rates can be explained by the fact that our survey involved people aged $\geq 65$ years old while Gutierrez-Fisac et al. $^{(38)}$ enrolled participants aged $\geq 60$ years, a stage of life with higher obesity prevalence than in other more advanced ages ${ }^{(39-41)}$. The present study also confirms that women presented higher BMI values than men in contrast with the fact that women presented more undernutrition prevalence too, measured by the MNA test, with statistically significant differences at all ages. Therefore, there were more men in the normal weight interval than women, who had higher presence in extreme nutritional situations. These data can be explained by the fact that $9 \cdot 2 \%$ of the undernourished elderly, according to MNA criteria, presented $\mathrm{BMI} \geq 30 \cdot 0$ $\mathrm{kg} / \mathrm{m}^{2}$, finding this situation more frequently in women (82\%) than in men (18\%).

Moreover, there were significant decreases in MNA score with age in both men and women, as expected ${ }^{(42,43)}$.

Finally, according to the total MNA score distribution across Spain, it can be mentioned that there were two areas in the north-east of the country, together with the metropolitan area of Madrid, which were in a better nutritional situation than the other Spanish regions. These areas include the six autonomous regions with the highest 
economic indicators ${ }^{(44)}$. Other recent studies among English people aged 65 years and older showed higher undernutrition risk in the northern regions than in southern ones ${ }^{(45,46)}$. Our survey suggests that, with the exception of the north-west, the north of Spain presents lower undernutrition risk rates than the middle-south part of the country.

\section{Conclusions}

The present study indicated that undernutrition prevalence among the community-dwelling elderly population in Spain is $4.3 \%$ and the prevalence of people at undernutrition risk is $25 \cdot 4 \%$, using the MNA test in two steps which showed a 'good to excellent' agreement between one another. Food intake decline and weight loss during the last three months were the items that correlated better with the total MNA score.

The results suggested that undernutrition increases with age and is higher in women than in men. On the other hand, women showed higher obesity prevalence while men had more individuals in the healthy weight range. Moreover, it appeared that elderly persons living in the north half of the country present less risk of undernutrition than those living in the south, except for the north-west area.

\section{Acknowledgements}

The authors declare that there are no conflicts of interest.

Sources of funding: The study was funded by the Spanish Pharmacists Council.

Author contributions: M.C. - first draft elaboration, training sessions, follow-up, reading of electronic questionnaires, data processing and analysis; A.G. - recruitment of pharmacists and coordination of data collection; D.A. - data processing, analysis and writing; A.S.-V. statistical assessment; M.A.M.-G. - design and statistical assessment; I.A. - design, general coordination; J.A.M. project leader, design, general coordination and supervision.

Acknowledgements: We are deeply indebted to every community pharmacist who participated in the survey for attending the training sessions and collecting the data, and to those pharmacists from each provincial pharmaceutical college and from the Spanish Pharmacists Council who coordinated all tasks. We also thank Ms Carmen de la Fuente and the other members of the SUN Study Group for their assistance in data processing.

\section{References}

1. Chen CC, Schilling LS \& Lyder CH (2001) A concept analysis of malnutrition in the elderly. J Adv Nurs 36, 131-142.
2. Drewnowski A \& Warren-Mears VA (2001) Does aging change nutrition requirements? J Nutr Health Aging 5, 70-74.

3. Brownie S (2006) Why are elderly individuals at risk of nutritional deficiency? Int J Nurs Pract 12, 110-118.

4. Coelho AK, Rocha FL \& Fausto MA (2006) Prevalence of undernutrition in elderly patients hospitalized in a geriatric unit in Belo Horizonte, MG, Brazil. Nutrition 22, 1005-1011.

5. Pirlich M \& Lochs H (2001) Nutrition in the elderly. Best Pract Res Clin Gastroenterol 15, 869-884.

6. Martinez JA, Velasco JJ \& Urbistondo MD (1994) Effects of pharmacological therapy on anthropometric and biochemical status of male and female institutionalized psychiatric patients. J Am Coll Nutr 13, 192-197.

7. Seiler WO (1999) [Nutritional status of ill elderly patients]. Z Gerontol Geriatr 32, Suppl. 1, I7-I11.

8. Casimiro C, Garcia de Lorenzo A \& Usan L (2001) [Evaluation of nutritional risk in ambulatory elderly patients]. Nutr Hosp 16, 97-103.

9. Commission of the European Communities (2005) Confronting Demographic Change: A New Solidarity Between the Generations. Green Paper 16.3.2005. Brussels: Commission of the European Communities.

10. IMSERSO (2006) Informe 2006. Las Personas Mayores en España. Datos Estadísticos Estatales y por Comunidades Autónomas. Observatorio de Personas Mayores. Madrid: Ministerio de Trabajo y Asuntos Sociales.

11. Green SM \& Watson R (2005) Nutritional screening and assessment tools for use by nurses: literature review. $J$ Adv Nurs 50, 69-83.

12. Sieber CC (2006) Nutritional screening tools - how does the MNA(R) compare? Proceedings of the Session held in Chicago May 2-3, 2006 (15 Years of Mini Nutritional Assessment). J Nutr Health Aging 10, 488-494.

13. Guigoz Y, Lauque S \& Vellas BJ (2002) Identifying the elderly at risk for malnutrition. The Mini Nutritional Assessment. Clin Geriatr Med 18, 737-757.

14. Vellas B, Villars H, Abellan G et al. (2006) Overview of the MNA(R) - its history and challenges. $J$ Nutr Health Aging 10, 456-465.

15. Guigoz Y \& Vellas B (1999) The Mini Nutritional Assessment (MNA) for grading the nutritional state of elderly patients: presentation of the MNA, history and validation. Nestle Nutr Workshop Ser Clin Perform Programme 1, 3-11.

16. Consejo General de Colegios Oficiales de Farmacéuticos (2005) Plan de Educación Nutricional por el Farmacéutico (PLENUFAR 3). Pamplona: Eurograf Navarra SL.

17. Suominen MH, Kivisto SM \& Pitkala KH (2007) Effects of nutrition education on professionals' practice and on the nutrition of aged residents in dementia wards. Eur J Clin Nutr 61, 1226-1232.

18. Rubenstein LZ, Harker JO, Salva A, Guigoz Y \& Vellas B (2001) Screening for undernutrition in geriatric practice: developing the short-form Mini-Nutritional Assessment (MNA-SF). J Gerontol A Biol Sci Med Sci 56, M366-M372.

19. Vellas B, Guigoz Y, Garry PJ, Nourhashemi F, Bennahum D, Lauque S \& Albarede JL (1999) The Mini Nutritional Assessment (MNA) and its use in grading the nutritional state of elderly patients. Nutrition 15, 116-122.

20. World Health Organization (2000) Obesity: Preventing and Managing the Global Epidemic. Report of a WHO Consultation. WHO Technical Report Series no. 894. Geneva: WHO.

21. Borecki IB, Higgins M, Schreiner PJ, Arnett DK, MayerDavis E, Hunt SC \& Province MA (1998) Evidence for multiple determinants of the body mass index: the National Heart, Lung, and Blood Institute Family Heart Study. Obes $\operatorname{Res}$ 6, 107-114. 
22. Douketis JD, Paradis G, Keller H \& Martineau C (2005) Canadian guidelines for body weight classification in adults: application in clinical practice to screen for overweight and obesity and to assess disease risk. CMAJ 172, 995-998.

23. Janssen I \& Mark AE (2007) Elevated body mass index and mortality risk in the elderly. Obes Rev 8, 41-59.

24. Martínez-González MA, Sánchez-Villegas A \& Faulin J (2006) Bioestadística Amigable. 2nd ed. Madrid: MartínezGonzález MA.

25. Margetts B (2003) FAO/WHO launch expert report on diet, nutrition and prevention of chronic diseases. Public Health Nutr 6, 323-325.

26. Raynaud-Simon A \& Lesourd B (2000) [Malnutrition in the elderly. Clinical consequences]. Presse Med 29, 2183-2190.

27. Omran ML \& Morley JE (2000) Assessment of protein energy malnutrition in older persons, part I. History, examination, body composition, and screening tools. Nutrition 16, 50-63.

28. Elia M, Zellipour L \& Stratton RJ (2005) To screen or not to screen for adult malnutrition? Clin Nutr 24, 867-884.

29. Villalobos Gamez JL, Garcia-Almeida JM, Guzman de Damas JM, Rioja Vazquez R, Osorio Fernandez D, Rodriguez-Garcia LM, del Río Mata J, Ortiz García C \& Gutiérrez Bedmar M (2006) [INFORNUT process: validation of the filter phase - FILNUT - and comparison with other methods for the detection of early hospital hyponutrition]. Nutr Hosp 21, 491-504.

30. Villamayor Blanco L, Llimera Rausell G, Jorge Vidal V, Gonzalez Perez-Crespo C, Iniesta Navalon C, Mira Sirvent MC, Martínez Penella M \& Rabell Iñigo S (2006) [Nutritional assessment at the time of hospital-admission: study initiation among different methodologies]. Nutr Hosp 21, 163-172.

31. Wanden-Berghe C, Sanz-Valero J, Jimenez M \& Hernandez M (2006) [Malnutrition of home-based hospital patients]. Nutr Hosp 21, 22-25.

32. Tur JA, Colomer M, Monino M, Bonnin T, Llompart I \& Pons A (2005) Dietary intake and nutritional risk among free-living elderly people in Palma de Mallorca. J Nutr Health Aging 9, 390-396.

33. Morillas J, Garcia-Talavera N, Martin-Pozuelo G, Reina AB \& Zafrilla P (2006) [Detection of hyponutrition risk in noninstitutionalised elderly]. Nutr Hosp 21, 650-656.

34. Kucukerdonmez O, Koksal E, Rakicioglu N \& Pekcan G (2005) Assessment and evaluation of the nutritional status of the elderly using 2 different instruments. Saudi Med J 26, 1611-1616.

35. Salminen $H$, Saaf $M$, Johansson SE, Ringertz $H$ \& Strender LE (2006) Nutritional status, as determined by the Mini-Nutritional Assessment, and osteoporosis: a crosssectional study of an elderly female population. Eur J Clin Nutr 60, 486-493.

36. Soini H, Routasalo P \& Lagstrom H (2004) Characteristics of the Mini-Nutritional Assessment in elderly home-care patients. Eur J Clin Nutr 58, 64-70.

37. Christensson L, Unosson M \& Ek AC (2002) Evaluation of nutritional assessment techniques in elderly people newly admitted to municipal care. Eur J Clin Nutr 56, 810-818.

38. Gutierrez-Fisac JL, Lopez E, Banegas JR, Graciani A \& Rodriguez-Artalejo F (2004) Prevalence of overweight and obesity in elderly people in Spain. Obes Res 12, 710-715.

39. Perissinotto E, Pisent C, Sergi G \& Grigoletto F (2002) Anthropometric measurements in the elderly: age and gender differences. Br J Nutr 87, 177-186.

40. Sundquist K, Qvist J, Johansson SE \& Sundquist J (2004) Increasing trends of obesity in Sweden between 1996/97 and 2000/01. Int J Obes Relat Metab Disord 28, 254-261.

41. Santos JL, Albala C, Lera L, Garcia C, Arroyo P, Perez-Bravo F, Angel B \& Peláez M (2004) Anthropometric measurements in the elderly population of Santiago, Chile. Nutrition 20, 452-457.

42. Saletti A, Lindgren EY, Johansson L \& Cederholm T (2000) Nutritional status according to mini nutritional assessment in an institutionalized elderly population in Sweden. Gerontology 46, 139-145.

43. Suominen M, Muurinen S, Routasalo P, Soini H, Suur-Uski I, Peiponen A, Finne-Soveri H \& Pitkala KH (2005) Malnutrition and associated factors among aged residents in all nursing homes in Helsinki. Eur J Clin Nutr 59, 578-583.

44. Instituto Nacional de Estadística (2005) Encuesta de Condiciones de Vida. Año 2004. Principales Resultados, p. 10. Madrid: INE.

45. Pentieva KD, Bates CJ, Prentice A \& Cole TJ (1999) North-south differences in some indices of vitamin $\mathrm{B}_{6}$ nutritional status in older British people. Int J Vitam Nutr Res 69, 371-377.

46. Elia M \& Stratton RJ (2005) Geographical inequalities in nutrient status and risk of malnutrition among English people aged 65 y and older. Nutrition 21, 1100-1106. 